\title{
Ari Hirvosen oikeudellisesta ajattelusta ja ajatuksista oikeudesta
}

\author{
JUHA KARHU
}

Haen tässä kirjoituksessa Ari Hirvosen oikeudellisen ajattelun peruselementtejä hyvin tietoisena siitä, että Hirvosta itseään innosti ajatus perustattomasta perustasta. Sovellan tarkasteluissani Panu Minkkisen ja Sami Santasen esittämää luonnehdintaa, jonka mukaan Hirvosen tutkimuksille ja pohdinnoille on ominaista tapa "tuoda harkitusti yhteen keskenään toisistaan eroavia ajatusrakenteita ja tiedonaloja. ... juuri kontaktin ansiosta tällaisten ajatusmallien välille syntyy itsessään merkityksellistä kitkaa ja jopa kiistaa." (Helsingin Sanomat 13.9.2021)

Ari Hirvonen oli sekä oikeusfilosofian että oikeusteorian dosentti. Suomalaisessa yliopistojärjestelmässä hakija päättää, minkä alan dosentuuria hän hakee. Hirvonen lienee "tupladosentuurillaan" halunnut tuoda julki sen, että hänen oikeudellinen ajattelunsa ilmenee kummankin alan tutkimuksissa. Toisaalta hänen valintansa luo myös merkityksellistä kitkaa ja kiistaa näiden kahden oppialan välille:oikeusfilosofian ja oikeusteorian välille muodostuu merkityksellistä kitkaa ja kiistoja. Kaikella filosofialla, myös oikeusfilosofialla, on itseisarvo ajatteluamme ja olemistamme pohdiskelevana filosofiana, filosofointina, kun taas oikeusteoria eri muodoissaan, kuten oikeuslähdeoppina, argumentaatioteoriana ja laintulkintaperiaatteina, on aina jollain tapaa yhteydessä oikeudenmukaisuuteen. Kiista oikeusfilosofian ja oikeusteorian välillä ei kuitenkaan tämän eron vuoksi ratkea oikeusfilosofian hyväksi. Oikeusteoria säilyttää omanlaisen asemansa muun muassa sen vuoksi, että se pystyy hyödyntämään oikeuden materiaalisuutta, eli sitä, että oikeus ilmenee yhteiskunnallisissa käytännöissä. Oikeusfilosofian ja oikeusteorian välinen kiista on esimerkki hyvästä "eriksestä", ratkeamattomasta ja siksi jatkuvasti hedelmällisestä jännitteestä. Koen, että Hirvosen "tupladosentuuri" on merkki ja vihje siitä, että hän haluaa tutkimuksillaan tunnistaa, kohdata ja ylläpitää tätä jännitettä, tätä hyvää ja hedelmällistä "eristä".

Hirvosen viimeisistä kirjoituksista kenties oikeusteoreettisin on viime vuonna Lakimies-lehdessä julkaistu "Konkreettinen oikeuslähdeoppi: normimateriasta rakenteisiin ja ratkaisutoimintaan" (2020a). Hirvosen tarkastelun lähtökohtia on, että moderni oikeus on yhteiskunnallinen instituutio, joka ei palaudu yksilöihin tai yhteisölliseen olemukseen eikä teologisiin tai metafyysisiin olettamuksiin. Siksi modernilla oikeudella ei myöskään ole universaaleja ajasta ja paikasta riippumattomia oikeuslähteitä. Tämän vuoksi oikeuslähdeoppi itsessään on aina normatiivispoliittinen kysymys: mille oikeuslähteille, kuten lainsäädännölle, ennakkopäätöksille ja käytännön vaikutuksille, annetaan ensisijainen painoarvo. Oikeuslähdeopin normatiiviset, käsitteelliset ja tosiasialliset elementit ovat siten sidoksissa yhteiskuntajärjestyksen rakenteiden ja vallankäy- 
tön muotoihin. Kirjoituksessaan Hirvonen kehittelee oikeuslähdeopin metateoriaa eikä kirjoitukseen sisälly luetteloa uusista oikeuslähteistä. Sen sijaan oikeusjärjestys nähdään konsonanssin ja dissonanssin, puiden ja rihmastojen kokonaisuutena, jossa materia ja rakenteet jatkuvasti aktualisoituvat oikeudellisissa käytännöissä. (Hirvonen 2020a.)

Perinteinen institutionaalisuudelle rakentuva oikeuslähdeoppi tarvitsee vastapoolikseen oikeuden materiaalisuuden ja elävän oikeuden tunnistavan ja tunnustavan uusrealistisen oikeusteorian. Vasta uusrealismin pohjalta voidaan muodostaa oikeuslähdeoppi, jossa pystytään yhdistämään nämä näennäisesti vastakkaiset elementit ja muodostamaan kestävä pohja oikeudenmukaiselle oikeudelliselle ratkaisutoiminnalle. Kuten havaitaan, kirjoituksessa strukturalismi on jännitteen tunnistamisen ja tunnustamisen väline, ei vastakkaisuudet tuhoava, repivä ratkaisu.

Hirvonen itse selvittää käsitystään oikeudesta seuraavasti:

En pidä oikeutta aukottomana ja ristiriidattomana järjestelmänä, vaan täynnä ristiriitoja olevana normien rihmastona, paradoksaalisena fragmentoituneena kokonaisuutena, murtuvana järjestelmänä, jota oikeusteoria sekä kokoaa kokonaisuudeksi luoden sille aina puutteellista koherenssia että myös purkaa. ${ }^{1}$

Oikeuden ja taiteen suhteet kiinnostivat Hirvosta koko hänen tutkijanuransa. Edustavana esimerkkinä tästä on vuonna 2004 Oikeus-lehdessä julkaistu artikkeli "Katseen kutsuminen. Caravaggio lain, yhteisön ja teoksen rajoilla." Kirjoituksen asetelma on oikeustieteellisen tutkimuksen lähtökohtana erikoinen ja valtavirtatutkimuksen näkökulmasta jopa omituinen: mitä ihmettä voisi uuden ajan alun uskonnollinen maalaus Matteuksen kutsuminen kertoa meille oman aikamme laista ja oikeudesta? Asetelman radikaalisuudesta huolimatta Hirvonen aloittaa helposti, viettelevän helposti. Caravaggion elämän käänteet käydään läpi ikään kuin vihjaten, että oman aikansa "pahan pojan" elinkaari paljastaisi maalaukseen kätkettyjä viisauksia oikeudesta. Juuri kun luki- ja on saanut tästä ajatuksesta kiinni, näkökulmaa vaihdetaan aikakauden kirkkomaalausten kulttuurihistoriaksi. Ehkäpä maalauksen vihjeet viittaavatkin paavinvallan vastustamiseen? Eipä niinkään, emme saa anakronisesti kirjoittaa omaa historiaamme aikakauteen, jota hallitsee sen oma episteme. Vasta kun uskallamme olla taideteoksen edessä paradoksaalisesti omana itsenämme, alkaa maalaus puhua meille, vasta silloin maalaus vastaa katseen kutsuun. Mitä maalaus sitten sanoo? "Katso, siinäkö oikeus - ja ihmettele!" (Hirvonen 2004.)

Hirvosen viesti on lopulta selvä: oikeuden ja taiteen yhteys ei tarkoita hänelle tekijänoikeudellisia pohdintoja teoskäsitteestä ja teoksen omaperäisyyden kriteereistä. Ei niin, etteikö niilläkin olisi käytännöllistä merkitystä mutta asetelma "oikeus ja taide" avautuu myös toisenlaisiin, keskenään jännitteisiin ja hedelmällisiin kiistoihin johtaviin ulottuvuuksiin. Mutta näin käy vain, jos taide nähdään yhtä itsenäisenä ja yhtä omalakisena kuin oikeuskin, oikeastaan vasta sitten kun taideteoksen kohtaaminen tapahtuu ilman etukäteen kiinnilyötyä "oikeudellisuudellisuuden" kehikkoa. Hirvosen omin sanoin:

Jos oikeus on tullakseen esiin taideteoksessa, niin sen on annettava tulla ilman, että sen esiintuloa alkaa etukäteen määräämään.

Oikeus ja taide -teemasta Hirvosen mestarintyö ovat Antiikin tragedian tarkastelut. Hirvosen vuonna 2000 tarkastetun oikeustieteen tohtorinväitöskirjan aiheena oli Sofokleen Antigone. Väitöskirjansa teemaa Hirvonen kuvaa kymmenen vuotta myöhemmin seuraavasti.

Antiikin tragediassa on kyse juuri oikeuden ja oikeudenmukaisuuden haennasta. Se on tapa käsitellä kysymystä oikeasta ja oikeassaolemisesta maailmassa. Se käsittelee traagisen sankarin hybristä, tämän rikosta ja uhmaa, ja esittää absoluuttisen valtiuden, tyrannian, tuomitsemista ja karkottamista kaupunkivaltiosta. Se esittää uusia tulkintoja perinteisestä mytologiasta, jotta vanhat sankaruuden, syyllisyyden ja sovituksen myytit voitaisiin omaksua uudessa poliittisessa yhteisössä siihen sopivassa muodossa. 
Antiikin tragediassa tulee esiin kysymys ihmisenä olemisesta, oikeassa olemisesta, olemisesta valtiossa suhteessa toisiin, itseen, olemiseen - ja jumaliin, jotka ovat poissa. Tragedia opettaa siis oikeudesta enemmän kuin hyllymetrit oikeustieteellistä kirjallisuutta.

Kaikki tragediat ovat siis oikeustragedioita. Hirvosen viimeiseksi jäänyt teos Ethics of Tragedy: Dwelling, Thinking, Measuring (2020c) jatkaa tuota teemaa mutta uudella tai kirkastetulla variaatiolla. Vähän uhkarohkeasti uskaltaudun esittämään tuon teoksen pohjalta ajatuksen tynkää, jota pitää vielä mietiskellä: Olisiko niin, että Antigonen velvollisuuksien ristiriita - Kreonin eli laillisen hallitsijan veljen hautaamisen kieltävän käskyn ja perinnetapojen mukaisesti sukulaisia sitovan hautaamisvelvoituksen - voisi sittenkin viitoittaa meitä etsimään kaiken etiikan perustavaa mittaa; kutsua etsintään, joka muutoin meidän aikakaudellamme jää "luonnon vastaiskujen", kuten ilmastokatastrofien ja pandemioiden, hirmuisuuksille?

Psykoanalyysi oli monin tavoin Hirvosen mielenkiinnon kohteena. Yksi lentoon lähtenyt idea oikeuden ja psykoanalyysin rinnakkain asettamisesta oli psykoanalyyttinen oikeustiede. Psykoanalyyttisessa oikeustieteessä oikeutta ja psykoanalyysia yhdistävä tekijä on symbolinen järjestys.

Oikeusjärjestys on olemassaolonsa velkaa symboliselle järjestykselle. Toimiakseen muutoinkin kuin väkivallan ja pelon järjestyksenä eli järjestyksenä, joka koetaan velvoittavana ja jolle annettaan hyväksyttävyysarvo, symbolisen järjestyksen pitää toimia ainakin jollain tavalla. Psykoanalyyttinen oikeustiede nimenomaan kykenee etenemään oikeus- ja moraalinormien sekä sen valtiollisten legitimaatiovajeiden tasolta perustavan symbolisen järjestyksen tasolle ja sen kriiseihin, joiden seurauksina ei ole vain romahtaneita valtioita vaan romahtaneita subjekteja. Kaiken kaikkiaan psykoanalyysi osoittaa sen, kuinka subjektina oleminen edellyttää normijärjestyksen. ... Psykoanalyysi antaa perustavamman kuvan normatiivisuuden ilmiöstä kuin oikeustiede, koska oikeus on vain yksi osa normatiivisuutta. ... Psykoanalyysi dekonstruoi oikeustieteen keskeisiä käsitteitä, kuten subjekti, vastuu, sopimus, tahallisuus ja tahto. Oikeustiede perustaa itsensä edelleen käsitykseen autonomisesta, rationaalisesta ja intentionaalisesta subjektista. Psykoanalyysi näyttää, että tämä on ainoastaan pieni osa subjektista, joka myös on kielen, symbolisen järjestyksen, halujen ja tiedostamattoman subjekti. Oikeusteorian tulisi päivittää itsensä käsittämällä subjekti uudelleen avaamalla ovensa psykoanalyysille.

Psykoanalyyttinen oikeustiede näyttäisi johtavan näennäisesti paradoksaaliseen käytännön lopputulokseen Kanadassa tapahtuneen henkirikoksen ("isänmurhan") rangaistavuudessa. Tapauksessa tekijä halusi hävittää koko Quebecin hallituksen mutta väärän ajoituksen vuoksi hän päätyi surmaamaan kolme hallintorakennuksen virkailijaa. Valtavirtarikosoikeus voisi mielentilatutkimuksen perusteella jopa jättää tekijän tuomitsematta rangaistukseen mielenterveyden häiriön vuoksi, koska asiassa esitettyjen psykiatristen lausuntojen mukaan teolta puuttui tekijän syyntakeettomuuden vuoksi täyden rangaistuksen edellyttämä tahallisuus. Psykoanalyyttinen oikeustiede taas nimenomaan toteaisi teon taustalla olevan Quebecin hallituksen samaistamisen tekijän tyrannimaiseen isään ja isänmurhan halun, ja siten teon tarkoituksen olevan aito. Tältä kannalta teko oli harkittu ja vaikuttimet olivat pohdittuja. Hirvoselle tutkijana on tyypillistä, että hän ottaa erittelyyn juuri tällaiset anomaliat. Asetelmassa psykoanalyysi ja syyntakeisuuden psykiatrinen luokittelu asetetaan vastakkain ilman yritystä valita niistä parempi tai oikeampi. Sen sijaan valtavirtatutkimuksen on syytä tunnistaa ja tunnustaa oma hämäryytensä syyntakeisuuden määrittelyssään. (mt.)

Tässä kirjoituksessa esiteltyjä Hirvosen tutkimuksia yhdistävänä punaisena lankana on käytetty tutkimusten kompositiota, asetelmaa, jossa toisistaan eroavien ajatusrakenteiden ja tiedonalojen tuominen harkitusti yhteen saa aikaan merkityksellisiä kiistoja. Kaikissa Hirvosen oikeustieteellisissä kirjoituksissa on myös sisällöllinen yhdistävä punainen lanka: oikeudenmukaisuuden taju. Esimerkiksi anarkismin kiinnostavuus oli hänen mukaansa siinä, millä muulla tavalla 
se voitaisiin sovittaa yhteen oikeudellisen ajattelun kanssa kuin koko oikeudellisen ajattelun kiistämisenä. Avain tällaiseen "sovittamattoman yhteensovittamiseen" on oikeudenmukaisuus: "anarkismi on kiinnostavimmillaan auktoriteetti-, instituutio-, uskonto- ja valtiokritiikeissään”. Sen sijaan Hirvosen mukaan oikeudenmukainen oikeusjärjestys abstrakteine oikeusnormeineen järjestää paremmalla tavalla ihmisten olemista yhteisössä ja sovittaa ihmisten vapauden yhteen. Oikeudenmukaisuuden taju muuntuu suorastaan oikeudenmukaisuuden raivoksi armottoman terävässä natsijuridiikan analyysissa (Hirvonen 2009). Hirvonen osoittaa askel askeleelta tai siirto siirrolta, miten kansallissosialistinen idea oikeudesta totaalisena lakina kutoutui osaksi Kolmannen valtakunnan oikeuskulttuuria valtion, Führerin tahdon, ja kansan käsitteiden kautta johtaen täydelliseen eettiseen sokeuteen. Hirvosen teksti on upea ja armoton erittely natsijuridiikasta - the devil is indeed in the legal details. Ja vihdoin myös Antigoneen loisto ja lumo taitaa liittyä siihen, miten hänen valintansa ja kohtalonsa puhuttelee meidän oikeudenmukaisuuden tajuamme. Hirvosen omassa tiivistyksessä kaikuu Immanuel Kantin ääni: "Oikeudenmukaisuus on siten oikeuden sisällä, joskin normeihin palautumattomana vaateena."

Hirvonen itse tiivistää oman oikeusfilosofisen kutsumuksensa:

Oma kutsumukseni on ihmetellä oikeutta, toisin sanoen yhä uudelleen ajatella oikeuden olemusta ja olemista, joka on aina myös kysymys sekä oikeudenmukaisuudesta ja oikeasta oikeudesta että toisten kanssa täällä olemisesta. Oikeusfilosofian tulee myös ajatella sitä, kuinka me maailmassa olevina olemme myös oikeudessa: mitä meidän oikeudessa olemisemme merkitsee ja mistä oikeassa olemisessa on kyse. Edelleen näen tärkeäksi kysyä sitä, onko oikeus, tai laajemmin normatiivisuus, olemisessa itsessään; vaatiko oleminen itsessään meitä vaikkapa vain olemaan, vai onko se toisten kanssa maailmassa olemiseen liittyvä ilmiö.
Oletan vahvasti, että Hirvonen alkoi kallistua jälkimmäiseen suuntaan ja painottaa yhä enemmän toisten kanssa olemista.

Hirvosen tekstit elävät ajassa. Niitä on erilaista lukea eri aikoina - mikä on toki truismi mutta samalla niin totta. Claude Levi-Strauss erotteli kulttuuri-ilmaisuissa kylmät ja kuumat asiat. Oikeuden alalla lainsäädäntö on kuuma, koska se muuttuu jatkuvasti; sen sijaan tapaoikeus on kylmä, koska sillä on pitkä kesto. Tämän erottelun näkökulmasta Hirvosen kirjoitukset ovat ilman muuta "cooleja", mutta silti osuvampaa on kuvata niitä kuumankylmiksi tai kylmänkuumiksi. Pitkän aikavälin teemat, lain ja oikeuden ikuisuuskysymykset, lomittuvat ajankohtaisiin. Hienona esimerkkinä tällaisesta kuumia ja kylmiä teemoja lomittavasta tarkastelusta on kirjoitus COVID-19 pandemiasta niin yksilöiden kuin yhteiskuntaruumiin sairastumisina (Hirvonen 2020b). Yhteiskunta ei olekaan vain yksilöiden summa tai vuorovaikutteinen yhteisö vaan jokin, jota voi tarkastella ruumiina, ennakoitavuutta edellyttävänä koneena. Ja jota kautta bioturvallisuushegemonialle voi esittää erilaisia vastarinnan muotoja - joista viimeisimpänä mutta ei vähäisimpänä Hirvonen viittaa rakastamisen, ystävyyden ja solidaarisuuden kykyihimme.

Teksteissäsi, hyvien kiistojen merkeissä, tapaan sinut, ystäväni, oikeusrunoilijan!

OTT JUHA KARHU on velvoiteoikeuden professori emeritus Lapin yliopistossa. 


\section{VIITTEET}

1 Olen tässä kirjoituksessa käyttänyt hyödykseni Samuli Hurrin ja Susanna Lindroos-Hovinheimon (2010) tekemää 50-vuotishaastattelua, jossa Hirvonen vastauksissaan taustoitti ja avasi ajatteluaan. Kirjoituksessa olevat sitaatit Hirvosen lausumista ovat tästä haastattelusta.

\section{KIRJALLISUUS}

Hirvonen, Ari (2000). Oikeuden käynti. Antigonen laki ja oikea oikeus. Helsinki: Loki-Kirjat.

Hirvonen, Ari (2004). "Katseen kutsuminen. Caravaggio lain, yhteisön ja teoksen rajoilla." Oikeus 3/2004, s. 256-276.

Hirvonen, Ari (2009). "Total Evil. The law under totalitarianism." teoksessa Law and Evil: Philosophy, Politics, Psychoanalysis. Abingdon \& New York: Routledge, s. 117-146.

Hirvonen, Ari (2019). "Hämärä syyntakeisuus." Kimmo Nuotion juhlakirja, SLY, s. 80-88.

Hirvonen, Ari (2020a). "Konkreettinen oikeuslähdeoppi: normimateriasta rakenteisiin ja ratkaisutoimintaan." Lakimies 7-8/2020 s. 954-971.

Hirvonen, Ari (2020b). "Poliittinen epidemologia. Virusajan normi ja poikkeus." Tiede \& edistys 4/2020, s. 322-347.

Hirvonen, Ari (2020c). Ethics of Tragedy: Dwelling, Thinking, Measuring. Oxford: Counterpress.

Hurri, Samuli \& Lindroos-Hoviheimo, Susanna (2010) "Oikeusfilosofian ydinkysymyksiä: Haastateltavana Ari Hirvonen” Lakimies 2010, 1089-1104. 